\title{
Records of Arorathrips mexicanus (Crawford, 1909) and Arorathrips fulvus (Moulton, 1936) (Thysanoptera: Thripidae) in the municipality of Araucária, Paraná, Brazil
}

\author{
Schuber, JM.*, Zawadneak, MAC. and Poltronieri, AS. \\ Departamento de Patologia Básica, Setor de Ciências Biológicas, Centro Politécnico, \\ Universidade Federal do Paraná - UFPR, \\ CP 19031, Bairro Jardim das Américas, CEP 80531-980, Curitiba, Paraná, Brazil \\ *e-mail: joseliaschuber@yahoo.com.br
}

Received June 12, 2008 - Accepted July 28, 2008 - Distributed November 30, 2008

The aim of this study was to record the occurrence of the species Arorathrips mexicanus (Crawford, 1909) and Arorathrips fulvus (Moulton, 1936) (Thysanoptera: Thripidae) in the municipality of Araucária, Paraná, Brazil.

Thrips were captured in Möericke traps installed originally for the collection of aphids in two commercial orchards with one being peach (cultivar Chimarrita) and the other nectarine (cultivar Bruna), in Araucária, Paraná (25 35' 35' S and 49 $24^{\circ} 37^{\prime} ' \mathrm{~W}$, altitude: $897 \mathrm{~m}$ ). The samplings in the peach orchard were conducted from July to December of 2005, and in the nectarine orchard from September to December of 2007. A total of 24 Möericke traps were installed randomly in each orchard. The traps were installed between rows and placed on $0.9 \mathrm{~m}$ high wooden supports. Weekly, the contents of each trap were transferred to a fine-mesh sieve, and with the help of forceps, the thrips were transferred to plastic containers, previously labeled, containing $70 \%$ ethyl alcohol. In each sampling, the traps were washed and the solution renewed. In the laboratory, the thrips were separated by morphospecies under a stereomicroscope and later mounted on permanent slides, according to the method of Palmer et al. (1989). Identification was performed with the aid of identification keys proposed by Mound and Palmer (1972) and Moritz et al., 2004.

Four specimens of $A$. mexicanus were collected in peach orchards in August 2005 and two of A. fulvus in nectarine orchards in September 2007. The principal differences between A. mexicanus and A. fulvus are the number of setae on the vertex of the head and the occurrence of the extension of the apex of the tibia (Mound and Marulo, 1996). A. mexicanus is characterized by having an extended apex of the tibia and 3 to 4 pairs of setae on the vertex of the head. This species has been encountered in cultivated pastures of subtropical areas of the world. A. fulvus possesses 15 to 20 setae on the vertex of the head and does not show a protrusion of the apex of the tibia along the outer edge of the fore tarsi (Mound and Marulo, 1996).

The genus Arorathrips comprises 13 New World species (Mound and Marulo, 1996). In Brazil, the species of this genus are not cited as pests of stone fruit trees, but have been reported to cause damage to monocotyledons (Monteiro, 2002). Almeida et al. (1994) collected two Arorathrips (= Chirothrips) mexicanus in Ambrosia polystachya DC in Arapoti, Paraná. In orchards in Araucária, where the samplings were made, the presence of some species of grasses (Poaceae) was verified, such as Avena strigosa Schreb, Brachiaria mutica (Forsk.) Stapf and Brachiaria plantaginea (Link) Hitchc. Therefore, new studies are needed utilizing more specific collection methods, to determine the species of plants that serve as hosts to thrips of the genus Arorathrips.

A. mexicanus are spread by grasses in tropical regions and on various Caribbean islands, as well as in Panama, Costa Rica and Brazil (São Paulo). A. fulvus has been reported in Hawaii, Texas and Brazil (Rio Grande do Sul and São Paulo) (Mound and Marulo, 1996). This work represents the first record of $A$. mexicanus and $A$. fulvus in the municipality of Araucária, Paraná, Brazil, and associates these insects with the vegetation in these orchards of stone fruit trees. These findings help amplify our knowledge of the entomofauna of thrips, as well as of the geographic distribution of the Arorathrips species in Brazil.

Acknowledgements - We thank Dr. Laurence Mound (CSIRO Entomology) for his help in the identification of the species and for valuable comments. We are also grateful to Dr. A. Leyva for his assistance with the translation of this work.

\section{References}

ALMEIDA, AMR., NAKAHARA, S. and SOSA-GÓMEZ, D., 1994. Thrips species identified in soybean fields in Brazil. An. Soc. Entomol. Bras., vol. 23, no. 2, p. 363-365.

MONTEIRO, RC., 2002. The Thysanoptera fauna of Brazil. In: Thrips, Plants, Tospovirus. In Proceedings of the 7th international symposium on Thysanoptera. Reggio Calabria, Italy. p. 325-340.

MORITZ, G., MOUND, LA, MORRIS, D. and GOLDARAZENA A., 2004. Trips ID - Pest thrips of world: an interactive identification and information system. Colling: CSIRO publishing. (CD-ROM).

MOUND, LA. and MARULLO R., 1996. The thrips of Central and South America: An introduction (Insecta: Thysanoptera). Florida: Memoirs on Entomology, International. 487 p.

MOUND, LA. and PALMER, JM., 1972. Grass-flower infesting thrips of the genus Chirothrips Haliday in Australia. Aust. J. Entomol., vol. 11, no. 4, p. 332-339.

PALMER, JM., MOUND, LA., DuHEAUME, GJ. 1989. CIE guides to insects of importance to man: Thysanoptera. Wallingford: CAB International. $74 \mathrm{p}$. 